should be regarded as universal in the hospital population."

There is conflicting evidence on whether the incidence of pulmonary embolism has risen during the last decade. It is complicated by the fact that different criteria have been employed in the various series of cases that have been published. It is therefore particularly interesting to consider the results in Morrell and Dunnill's recent paper ${ }^{1}$ together with a retrospective study carried out in the same group of hospitals by Morrell, S. C. Truelove, and A. Barr. ${ }^{2}$ They produced reasoned evidence to show that the incidence of pulmonary embolism found in routine necropsy examinations increased from $3.8 \%$ in 1952 to $10.6 \%$ in 1961 .

It is remarkable how little we know about both the cause and the frequency of this widespread and often fatal condition. It is to be hoped that Morrell and Dunnill will continue their investigation, perhaps with a smaller sample, in order to monitor the true incidence of pulmonary embolism at necropsy from year to year at Oxford, where so much work has already been done on this mysterious disease. Further knowledge will be of great importance not only to hospital patients but also to many others, including the increasing number of young women on oral contraceptives.

\section{Temporary Halt}

The Ministry of Health has been wise to assent to the B.M.A.'s request for a temporary halt in the creation of new full-time hospital medical assistant posts. The Annual Representative Meeting, in an acrimonious debate, forcefully rejected the grade " as currently defined," and a pause now for reflection will allow the matter to be looked at more objectively.

Some much-needed facts should come out of the Ministry's proposed inquiry referred to in a letter from its Deputy Chief Medical Officer printed in the Supplement (page 98). The number of existing full-time medical assistant posts is variously estimated at from 700 to over 1,000 , and it is not known how many of these were conversions from the now non-existent junior hospital medical officer grade and from other grades and how many were new posts. Nor apparently is it known how many proposals for posts by hospital boards have been rejected and how many accepted by the Advisory Committee for Consultant Establishments. When these figures are available it will be possible to see how much the grade has grown since it began in 1964 . It would also be interesting to know how many doctors had applied for posts as medical assistants.

As a further reaction to the present disagreement about the permanent grades of hospital medical staff the Health Ministers are to $\mathbf{a s k}^{2}$ a working group of consultants and hospital junior doctors, together with the Chief Medical Officers of the Health Departments, to consider the question of the definition of the responsibilities and functions of the consultant grade. The Ministers are not alone in thinking that the solution to the problem lies in getting these definitions right. The working group will not lack references, reports, and opinions on the matter. Its consultant and junior doctor members are to be chosen by the Ministers and not nominated by the profession.

\footnotetext{
Brit. med. F. Suppl., 1968, 3, 8

2 Brit. med. F., 1968, 3, 323.
}

The results of both these inquiries-which are expected before the end of the year-will be reported to the medical profession and discussed with its representatives, but it seems probable that the Ministers are about to take their own line in the matter of hospital medical staffing. In trying to meet the pressing needs of the hospital service it would be shortsighted of them to neglect the requirements of medicine or the legitimate interests of doctors.

\section{Care of Hospital Staff}

Working day in day out in the presence of sick people, members of hospital staffs are exposed to many unusual risks to health. Indeed, the wonder is that healthy and energetic people can mingle continually with the sick and dying with so little ill effect. Nothing less than the most scrupulous hygiene and strictest discipline are the accepted lot of everyone working in these circumstances, but that accidents happen is evident from time to time, and new hazards are continually being added to the old. Sensitivity reactions among nurses to streptomycin ${ }^{1}$ and fatal hepatitis among the staff managing renal dialysis ${ }^{2}$ are two of the risks noted in recent years. In fact the opportunities for transmission of infection must always cause concern. The hazards of $x$ rays demand constant vigilance but are now brought under control, though they were certainly not when the Adrian committee first reported 12 years ago. ${ }^{3}$ Perhaps the least studied risk to staff is the emotional strain of looking after sick people all the time, which may be reflected in the abnormally high suicide rate found in the medical profession. ${ }^{4}$

For many years hospitals have made arrangements for the medical care of their staff, usually charging a doctor on the staff with that duty. The tasks these doctors have undertaken have varied considerably from one hospital to another and may sometimes have been rather haphazard. Consequently in 1965 the Central and Scottish Health Services Councils appointed a joint committee " to review the existing provision for the care of the health of hospital staff of all grades and to make recommendations."

Its report $^{5}$ was published last week, and its main recomdation is that " hospital authorities should aim at setting up, as an independent but integrated part of their administrative structure, an occupational health service under the direction of a suitably qualified medical officer." The functions of this service would be to examine members of the staff not as a routine but as the nature of their employment makes necessary, to advise on hygiene, and to provide the initial treatment of those who become ill or are injured at work. The doctor in charge, the committee believes, should usually be a general practitioner, but it suggests that in some cases doctors in the " middle grade hospital staff" might also wish to undertake such work. In either case he should have "some specialized knowledge of occupational and preventive medicine." The report emphasizes that the occupational health service should be independent of the hospital administrative structure, and

\footnotetext{
1 Wilson, H. T. H., Brit. med. F., 1958, 1, 1378.

Brit. med. F., 1965, 2, 1199.

- Medical Research Council, The Hazards to Man of Nuclear and Allied Radiations, 1956, Cmd. 6780. H.M.S.O.

- Brit med 7 1964, 1, 789.

s The Care of the Health of Hospital Staff, Report of Joint Committee of the Central and Scottish Health Services Councils (Chairman, Sir Ronald Tunbridge), 1968. H.M.S.O.
} 
to ensure that it is the doctor in charge should be responsible direct to the hospital management committee, board of management, or board of governors. Further, to provide expert advice in occupational health, the report recommends the appointment of a senior doctor from industry or a university department to the regional hospital board.

In general this report will be welcomed, and especially its emphasis on trying out different schemes, for what may seem to a tidy mind to be haphazard arrangements have often grown up to suit the requirements of a particular hospital and its staff, and in doing so may be more humane and effective than one that is universal and official. In any plans to develop a new service, however, the arrangements at present in force will need to be borne in mind, for the position of those running them must be safeguarded.

Writing on accommodation of staff, which certainly has a bearing on health and hygiene, the committee noted from personal visits that some of it was "appalling" and did not indeed reach the minimum standards laid down by Acts of Parliament. This sort of thing was not even unusual, but "widespread." As the hospital service employs more than half a million people, of whom $75 \%$ are women, the committee's strictures on working and living conditions deserve the urgent attention of the departments of health. Much could be done to remedy them long before a full occupational health service is established. Meanwhile experimental schemes, of which several have been started, to provide a health service for hospital staffs will be studied with interest.

\section{Herpes Encephalitis}

Herpes simplex virus was first isolated in 1941 from the brain of a 4-week-old infant who died after an acute encephalitis. ${ }^{1}$ During the next 20 years it was identified in several cases of neurological disease varying from aseptic meningitis $^{2}$ to acute encephalitis. ${ }^{34}$ The total number of cases reported was small, and it did not appear that herpes contributed much to the total number of non-bacterial infections of the central nervous system.

This is still probably true today in respect of herpes as a cause of aseptic meningitis. Perhaps $1 \%$ or fewer cases can be attributed to herpes. ${ }^{5}$ But it is now known to cause a considerable number of severe infections of the central nervous system, such as acute necrotizing encephalitis. This type of encephalitis, first reported by Van Bogaert and his colleagues ${ }^{6}$ and associated with intense neuronal necrosis, is being identified with increasing frequency. ${ }^{7}$ Herpetic encephalitis is by no means so rare as it was generally assumed to be, but because of its sporadic occurrence and mode of presentation the cause may be overlooked.

Patients usually present with an acute febrile illness with headache, confusion, and convulsions. There may be clinical and radiological evidence of an expanding lesion in the brain, particularly in the temporal lobes, so that distinction from an abscess or tumour is important. The need for early and accurate diagnosis is further emphasized by the fact that specific treatment with the antiviral compound idoxuridine, if it is to have much chance of success, should be administered as early as possible before the neuronal necrosis has progressed too far.

Herpes encephalitis occurs as an acute and sporadic illness in any age group, but there are differences between the disease in infants and in older children and adults. In infants the central nervous system is usually attacked as part of a disseminated infection, often involving the liver and adrenals, and frequently the skin too. Massive haemorrhagic necrosis, with softening of many parts of the brain, perivascular cuffing, and intranuclear inclusions, is found at necropsy.

W. Haymaker and his colleagues ${ }^{8}$ reviewed 42 cases of herpetic encephalitis, of which seven were of the infantile type. In the remaining 38 adults the illness was confined to the nervous system. The onset was acute, with headache, fever, nausea and vomiting, confusion, loss of memory, and profound agitation. The average length of the illness was ten days, but one patient survived four years. The gross changes at necropsy were softening with haemorrhagic necrosis of grey and white matter. A more recent review by $\mathbf{W}$. Leider and his co-workers ${ }^{9}$ from California of 18 cases of herpes simplex infection of the central nervous system included 15 cases of encephalitis. Five of these were infants and young children and the remainder were adults aged 17 to 71 years. Of interest is the fact that of the ten adult patients only one died, three remained in hospital, three had permanent loss of memory or behavioural disorder, and five were normal on discharge. In three of these adult patients a history was obtained of previous recurrent labial herpes, and all three had complement-fixing antibody in serum taken within four to seven days of the onset of the encephalitic illness. These and some of the others showed a rise in C.F. antibody, and though the C.F. test is less reliable than the neutralization test in diagnosis of infections, because of cross-reactions between herpes and varicella-zoster viruses, ${ }^{10}$ it seems probable that several of these cases resulted from reactivation of latent virus. Others are probably due to primary infection.

Many other cases have been reported in the past seven years from Great Britain and abroad, nearly all of which fit the diagnosis of acute necrotizing encephalitis. Diagnosis during life is extremely difficult, even if it is suspected, unless specific virological tests are employed. F. O. MacCallum and his colleagues ${ }^{11}$ reported two cases presenting as a brain abscess in which the definitive diagnosis was made by isolation of the virus from cortical biopsies in human amnion cell cultures. J. H. Adams and W. B. Jennett ${ }^{12}$ have reported

Smith, M. G., Lennette, E. H., and Reames, H. R., Amer. F. Path. $1941,17,55$.

2 Armstrong, C., Publ. Hlth Rep. (Wash.), 1943, 58, 16.

W Whitman, L., Wall, M. J., and Warren, J., f. Amer. med. Ass., 1946, 131, 1408 .

- Zarafonetis, C. J. D., Smadel, J. E., Adams, J. W., and Haymaker, W. Amer. F. Path., 1944, $20,429$.

Macrae, A. D., in Virus Meningo-encephalitis, Ciba Foundation Study Group No. 7, p. 6, ed. G. E. W. Wolstenholme and M. P. Cameron. 1961. London.

Van Bogaert, L., Radermecker, J., and Devos, J., Rev. neurol., 1955, 92, 329.

Brit. med. F., 1966, 1, 1497. Symposium on Viral Encephalitis, p. 95, ed. W. S. Fields and R. J. Symposium on Viral Encephalitis,

- Leider, W., Magoffin, R. L., Lennette, E. H., and Leonards, L. N. R., New Engl. F. Med., 1965, 273, 341 .

10 Ross, C. A. C., Sharpe, J. H. S., and Ferry, P., Lancet, 1965, 2, 708. MacCallum, F. O., Potter, J. M., and Edwards, D. H., Lancet, 1964, 2,332 .

2 Adams, J. H., and Jennett, W. B., f. Neurol. Neurosurg. Psychiat., $1967,30,248$.

is Harland, W. A., Adams, J. H., and McSeveney, D., Lancet, 1967, 2, 581.

is Breeden, C. J., Hall, T. C., and Tyler, H. R., Ann. intern. Med., 1966, 65, 1050 .

is Evans, A. D., Gray, O. P., Miller, M. H., Jones, E. R. V., Weeks, R. D., and Wells, C. E. C., Brit. med. 7 ., 1967, 2, 407.

10 Marshall, W. J. S., Lancet, 1967, 2, 579.

1 Buckley, T. F., and MacCallum, F. O., Brit. med. f., 1967, 2, 419.

Olson, L. C., Buescher, E. L., Artenstein, M. S., and Parkman, P. D., New Engl. F. Med., 1967, 277, 1271.

10 Blackwood, W., Dudgeon, J. A., Newns, G. H., and Phillips, B. M. Brit. med. f., 1966, 1, 1519 